\title{
Morphometric, Anatomic and Radiographic Study of Bone of the Pelvic Limb of Endangered Patagonian Huemul Deer (Hippocamelus bisulcus)
}

\author{
Estudio Morfométrico, Anatómico y Radiográfico de los Huesos del Miembro Pélvico \\ del Huemul Patagónico en Peligro de Extinción (Hippocamelus bisulcus)
}

Paulo Salinas $^{1}$; Abigail Arenas-Caro ${ }^{\mathbf{~}}$, Samuel Núñez-Cook ${ }^{\mathbf{1}}$;

Luis Moreno²; Escarlet Curihuentro ${ }^{2,4}$ \& Fernando Vidal ${ }^{3,4,5,6}$

\begin{abstract}
SALINAS, P.; ARENAS-CARO, A.; NÚÑEZ-COOK, S.; MORENO, L.; CURIHUENTRO, E. \& VIDAL, F. Morphometric, anatomic and radiographic study of bone of the pelvic limb of endangered Patagonian huemul deer (Hippocamelus bisulcus). Int. J. Morphol., 38(3):747-754, 2020.

SUMMARY: Currently, the Patagonian huemul (Hippocamelus bisulcus) is endangered. Anatomical studies focused on understanding the anatomy of the deer most threatened by extinction in South America is a challenge for anatomists, veterinarians and biologists. Research carried out for its conservation has focused mainly on its ecology and pathology, leaving gaps in anatomical knowledge, which is basic and important for a comprehensive understanding of this species. Gross anatomy and radiography of the skeleton of the pelvic limb was performed in three adult Patagonian huemul. Bone specimens of three skeletally mature Patagonian huemul deer were used for gross osteological and radiographic studies. This study was conducted to reveal the morphometric and morphological features of the ossa membri pelvini of the Patagonian huemul. The main findings suggest the presence of powerful extensor muscles in the coxofemoral, femorotibial and tarsal joints, useful during walking, jogging and propulsion in deer. In general, the MNF of Patagonian huemul differ in position with respect to domestic ungulates. In addition, the presence of a notch or obturator canal was observed, with variability in morphology and development among the specimens.
\end{abstract}

KEY WORDS: Anatomy; Deer; Osteology; Huemul; Skeleton; Wildlife.

\section{INTRODUCTION}

The Huemul is an endemic deer from Chile and Argentina, is internationally declared endangered, with fragmented populations and decreasing number of individuals due to anthropogenic causes, such as human encroachment and agriculture, limiting accessibility to the valleys and eliminating seasonal migration (Black-Decima et al., 2016), and is the only large native herbivore to reside in most of the sub-antarctic false-beech forest habitat occurring in Chile and Argentina (Flueck \& Smith-Flueck, 2005). In the year 2003 it was declared an endangered species by the International Union for the Conservation of Nature, having lost $99 \%$ of its population during the past 100 years (Vila et al., 2006). The morphological and anatomical information is scarce, namely due to the Chilean and Argentinian legislation, which protects these animals not only from hunting, but also from research. Among the limited morphological data, the research carried out by Flueck \& Smith-Flueck (2014) in the Argentinian Patagonia stands out, who describe the huemul as a deer of short and stocky members, being compared with ungulates of the caprinae family of mountainous habits such as Cabra ibex, Rupicapra rupicapra, Ovis canadensis and Oreamnos americanus. After the publication of paleontological antecedents, it was stated that the huemul is a mountain deer with structural characteristics typical of climbing animals that live at heights. However, currently this statement has been questioned. The specific intra-species shape and proportion

\footnotetext{
${ }^{1}$ Institute of Biology, Faculty of Sciences, Pontificia Universidad Católica de Valparaíso, Valparaíso, Chile.

${ }^{2}$ School of Veterinary Medicine, Universidad Santo Tomás, Temuco, Chile.

${ }^{3}$ Unit of Wildlife Conservation and Management, Universidad Santo Tomás, Temuco, Chile.

${ }^{4}$ Fauna Andina, Wildlife Conservation and Management Center, Villarrica, Chile

${ }^{5}$ IUCN, Deer Specialist Group, Johnny Cake Ridge Road, Apple Valley, MN, USA.

${ }^{6}$ Fundación Huilo Huilo, Wildlife Department, Neltume, Panguipulli, Chile.
} 
of the length of the bone structures that are part of the thoracic and pelvic members is not static and is influenced by echogeography, nutrition, physiology and other factors that affect the thoracic and pelvic limbs.

In Chile, conservation strategies such as captive reproduction, ex situ conservation projects have been implemented, nonetheless any efforts so far, have been insufficient. Undoubtedly, the greatest impact on the population decline is caused by infectious diseases transmitted by domestic livestock, such as parapoxvirus (Vila et al., 2019), caseous lymphadenitis (Corynebacterium pseudotuberculosis, Morales et al., 2017), bovine paratuberculosis (Mycobacterium avium; Salgado et al., 2017), bovine viral diarrhea (Corti et al., 2013) and sheep scab (Psoroptes ovis; González-Acuña et al., 2009), among others. The demand to avoid the total extinction of the Patagonian huemul has increased the need to generate new knowledge. Currently, no literature documents the anatomical and morphometric characteristics of this particular deer. The skeleton of animals is an essential structure that serves as a reference point to identify or gain access to other structures or cavities of the animal system. Therefore, the anatomical knowledge will not only benefit anatomists, but also help improve conservation strategies related to the prevention of infectious diseases, clinical practice and new surgical protocols. The aim of this study was to provide the normal and detailed gross anatomy of the ossa membri pelvini of the Patagonian huemul including a functional interpretation of this, as a reference for clinical and conservation use, biomedical research and teaching purposes.

\section{MATERIAL AND METHOD}

Specimens. Three pelvic limb skeleton of Patagonian huemul (Hippocamelus bisulcus) were used, which were denominated as: "specimen-A", male specimen, deceased for causes not related to this research, obtained by exhumation one year prior to the study (Source: Fauna Andina, Pedregoso sector, Villarrica $\left(39^{\circ} 16^{\prime} 00^{\prime \prime S}\right.$, $\left.72^{\circ} 13^{\prime} 00^{\prime \prime} \mathrm{W}\right)$ in La Araucania Region, Chile; 227 m.a.s.1., collected on October 20, 2014) within the Resolution framework No. 1490 (December 22, 2003) of the Agricultural and Livestock Service of Chile (SAG), "specimen-B" and "specimen-C" belonged to the collection of the Chilean National Museum of Natural History (NMNH), both of unknown sex ("B": NMNH Nº1947; source: Villa Cerro Castillo, Aysen, in General Carlos Ibáñez del Campo Region, 4607'15.0"S, 7209'20.0"W, 404 m.a.s.1., collected on January 3, 2005; and "C": NMNH/ MAM N¹948, Chilean origin, no background).
Gross Anatomy and Morphometry: A descriptive and morphometric study of the pelvic limb skeleton of huemul was made from simple visual observation, with calipers and a flexible tape measure. To avoid observer bias, the bones were described and measured by three independent evaluators. In long bones we measured: total length, narrowest width of diaphysis and greater width of epiphysis. In flat bones, length margins were measured. Obstetric axes were measured in the coxal bone: dorsal axis, which was measured in the cranial opening of the pelvis (between the lower portion of sacrum wings), middle axis (between the tubercles of psoas minor muscle) and ventral axis (between iliopubic eminences). In the caudal opening of the pelvis: middle axis (between ischial spines) and caudal axis (between ischial tuberosities). In addition, vertical axes were measured, such as: conjugata vera (distance between sacral promontory and pubic tubercle) and vertical diameter (between pubic tubercle and ventral surface of the sacrum). These among other variables specific to each bone. The obtained data (mean \pm SD) were sorted in Excel tables (Microsoft Office Professional Plus 2013, Windows 7 Professional 2009). The terminology used in this study is that of Nomina Anatomica Veterinaria 6th Edition (Revised) (International Committee on Veterinary Gross Anatomical Nomenclature, 2017).

Radiography: The radiographic study was used to write the opacity and density of the compact and trabecular bone tissue. The radiographic findings were correlated with the bone samples. The images were obtained by indirect digital radiology. An ORANGE $9020 \mathrm{HF}$ X-ray generator (EcoRay Co., LTD., Seoul, Korea) was used, with a configuration of $60 \mathrm{Kv}$ and $2.5 \mathrm{mAs}$, at a distance of $100 \mathrm{~cm}$. Radiographic carbon fiber chassis with phosphor panel of 24 x $30 \mathrm{~cm}$ was used. The digitalization of the images was carried out through the portable veterinary radiography (CR) system (iCRcoTM, iCR Chrome Vet model, USA). The images were obtained using DICOM XCTM software using a Dell Inspiron 157000 Series PC with CORE i7 processor. The radiographic findings were correlated with the bone samples.

\section{RESULTS}

The pelvic limb bones were represented by the coxal bone (os coxae) -ilium, ischium and pubis- femur, tibia, tarsus and foot bones. Both coxal bones articulate forming a smooth and relatively concave pelvic floor (Fig. 1A). Ilion and ischium presented large radiolucent areas (trabecular bone tissue), especially in the region of the ala ossis ilii and in the region of the ischium table. The region of the body of the ilium and the acetabulum presented radiopaque areas 

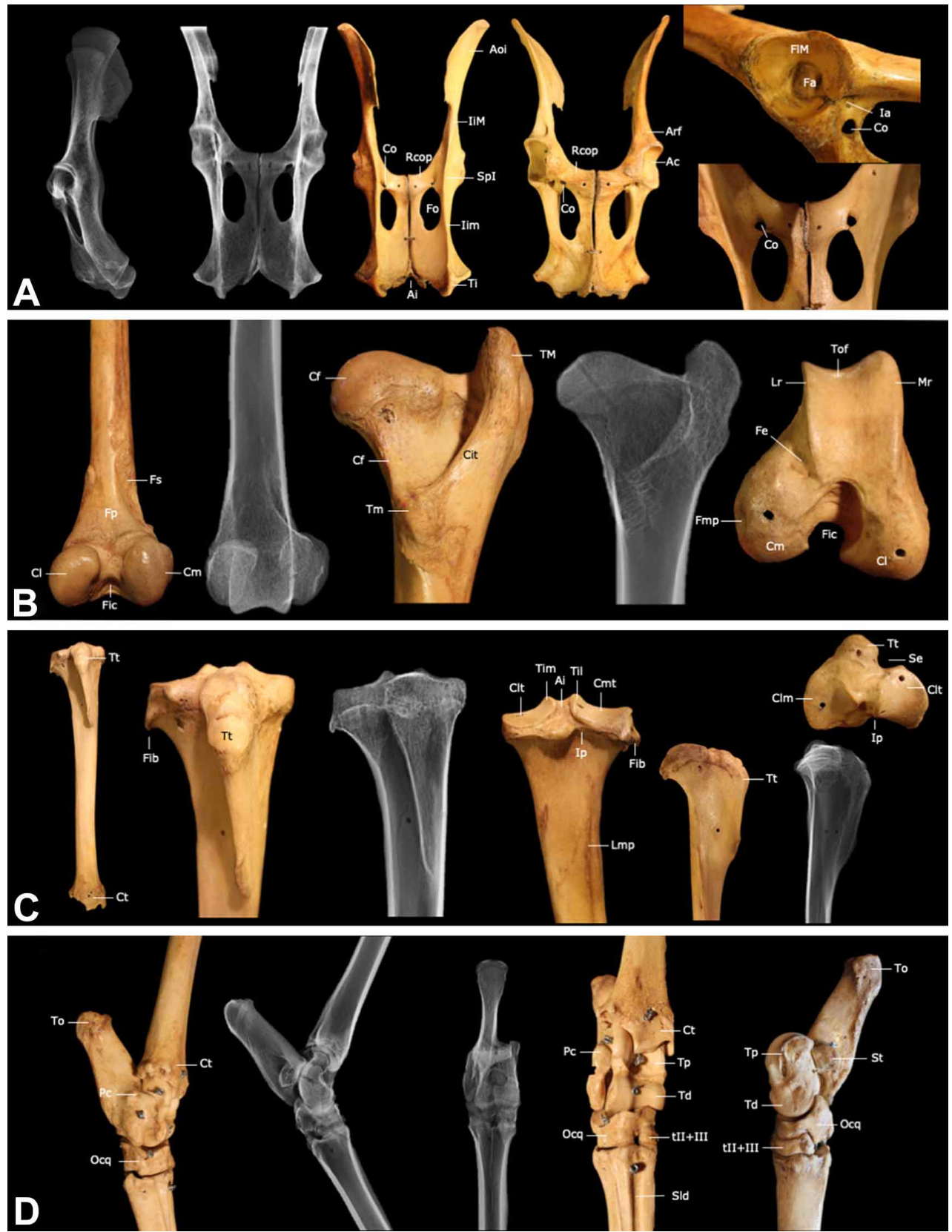

Fig. 1. Bones of the pelvic limb of Endangered Patagonian Huemul Deer. A Os coxae, B Os femoris, C Tibia and F: Ossa tarsi. Aoi, Ala ossis ilii; Ti, Tuber ischiadicum; Rcop, Ramus cranialis ossis pubis; IiM, Incisura ischiadica major; Si, Spina ischiadica; Iim, Incisura ischiadica minor; Co, Canalis obturatorius; Ai, Arcus ischiadicus; Fo, Foramen obturatum; Ac, Acetabulum; Arf, Area lateralis m. recti femoris; FIM, Facies lunata, pars major; Fa, fossa acetabuli; IA, Incisura acetabuli; Fs, Fossa supracondylaris; Fp, Facies poplitea; Fic, Fossa intercondylaris; $\mathrm{Cl}$, Condylus lateralis; $\mathrm{Cm}$, Condylus medialis; TM, Trochanter majus; Tm, Trochanter minus; Cf, Caputfemoris; Cit, Crista intertrochanterica; Cf, Collum ossis femoris; Tof, Trochlea ossis femoris; Lr, Lateral ridge; Mr, Medial ridge; Fe, Fossa extensoria; Fmp, Fossa m. poplitei; Tt, Tuberositas tibiae; Ct, Cochlea tibiae; Fib, Reminiscence of the fibula; Clt, Condylus lateralis; Cmt, Condylus medialis; Tim, Tuberculum intercondylare mediale; Til, Tuberculum intercondylare laterale; Ai, Area intercondylaris; Ip, Incisura poplitea; Lmp, Linea m. poplitei; Se, Sulcus extensorius; To, Tuber olecrani; Pc, Processus coracoideus; St, Sustentaculum tali; Tp, Trochlea proximalis; Td, Trochlea distalis; Ocq, Os centroquartale; tII+III, Os tarsale II et III; Sld, Sulcus longitudinali.s dorsalis. (compact bone tissue). The measurements of the obstetrics and vertical axes in coxal bones are describes in Table I and Figure 2. The measurements of bones of the pelvic member are described in Table II.

The ilium (os ilium) had a triangular shape, the dorsal margin corresponded to the greater sciatic notch and to dorsal and caudal iliac spines, and the cranial margin was the iliac crest; the cranio-lateral angle was the coxal tuber, which had an internal and external lip, and the dorso-medial angle corresponded to the sacral tuber. The sacropelvic (medial) surface of the wing presented a smooth iliac face and a rough auricular face. The gluteal (lateral) surface was smooth and had more rough gluteal lines in "specimenB" and "specimen-C". The MNF was located on the medial side of the body. Also, a short arcuate line that ended medial to the area of the rectus femoris muscle insertion was observed.

Ischium (os ischii) presented a body (corpus ossis ischii), a table (tabula ossis ischii) and a ramus (ramus ossis ischii). The table was square, its caudo-lateral angle was the ischial tubercle in which three tuberosities were observed: dorsal, medial and lateral. The last ones 


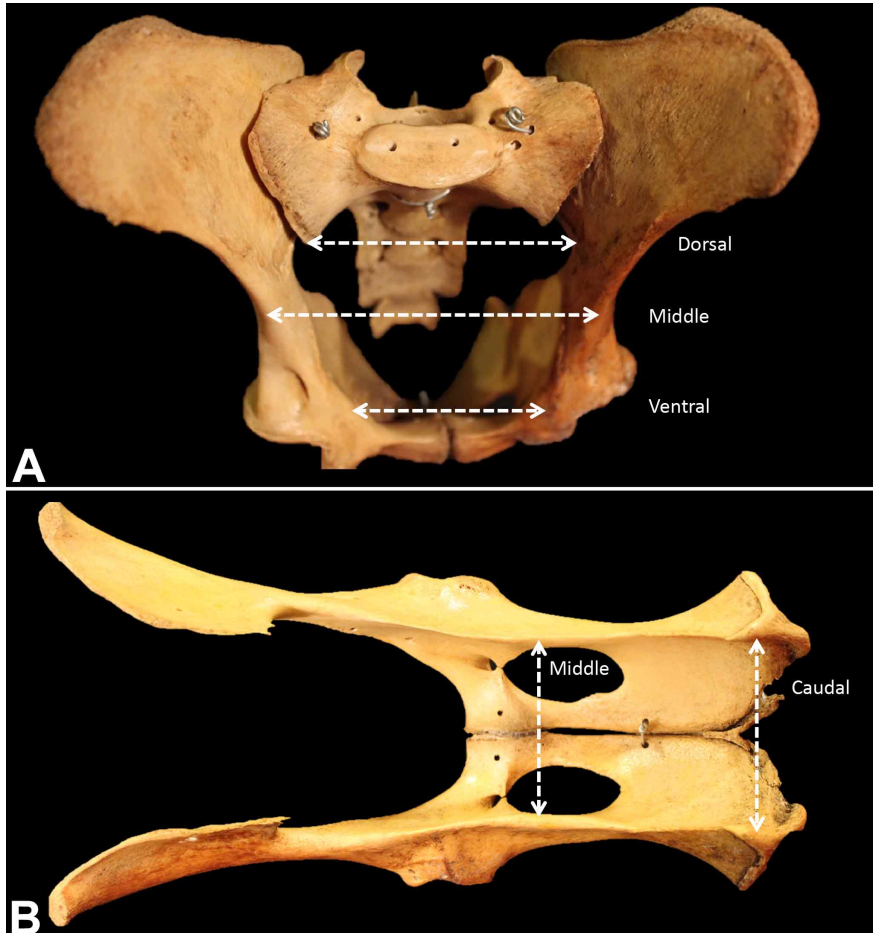

Fig. 2. Obstetric axes in the coxal bone. A: cranial opening of the pelvis, dorsal axis (between the lower portion of sacrum wings), middle axis (between the tubercles of psoas minor muscle) and ventral axis (between iliopubic eminences). B: caudal opening of the pelvis: middle axis (between ischial spines) and caudal axis (between ischial tuberosities). In addition, vertical axes were measured, such as: conjugata vera (distance between sacral promontory and pubic tubercle) and vertical diameter (between pubic tubercle and ventral surface of the sacrum).

Table I. Morphometry of the patagonian huemul deer pelvic girdle (mean $\pm \mathrm{SD})$.

\begin{tabular}{lc}
\hline & Length $(\mathrm{mm})$ \\
\hline Pelvic inlet & \\
Dorsal & $78.07 \pm 8.75$ \\
Medium & $77.36 \pm 2.82$ \\
Ventral & $66.67 \pm 6.93$ \\
Conjugata vera & $114.00 \pm 1.74$ \\
Vertical diameter & $86.16 \pm 7.16$ \\
Pelvic outlet & \\
Medium & $71.63 \pm 15.26$ \\
Caudal & $60.74 \pm 8.17$ \\
Others & \\
Symphysis & $174.12 \pm 105.78$ \\
Width at ischial spine & $80.10 \pm 18.33$ \\
Maximum width of ischial tuberosity & $116.39 \pm 12.47$ \\
\hline
\end{tabular}

were more developed in "specimen-B", as were medial and lateral in "specimen- $\mathrm{C}$ ". It presented a smooth dorso-medial and a rough ventro-lateral surface, with a tuberosity projected
Table II. Morphometry of the patagonian huemul deer hindlimb (mean \pm SD).

\begin{tabular}{lcc}
\hline & \multicolumn{2}{c}{ Length (mm) } \\
& Right $\mathrm{n}=3$ & Left $\mathrm{n}=3$ \\
\hline Pelvic Girdle & $291.15 \pm 33.96$ & $283.85 \pm 17.84$ \\
Coxal bone & $60.60 \pm 3.72$ & $59.31 \pm 5.79$ \\
Width of ilium wing & $45.79 \pm 6.31$ & $44.97 \pm 5.73$ \\
Obturator foramen & $24.58 \pm 0.48$ & $25.70 \pm 3.83$ \\
Depth of acetabulum & $9.71 \pm 2.37$ & $9.07 \pm 1.51$ \\
Obturator canal & & \\
Femur & $247.52 \pm 21.33$ & $238.17 \pm 14.77$ \\
Total & $114.52 \pm 10.52$ & $106.93 \pm 11.89$ \\
Neck & $64.28 \pm 2.84$ & $62.51 \pm 2.27$ \\
Width of proximal epiphysis & $21.38 \pm 2.70$ & $19.67 \pm 0.93$ \\
Width of diaphysis & $60.26 \pm 2.47$ & $59.43 \pm 2.34$ \\
Width of distal epiphysis & & \\
Patella & $34.70 \pm 2.25$ & $34.28 \pm 3.73$ \\
Base of patella & $41.41 \pm 1.48$ & $39.05 \pm 3.65$ \\
Medial border & $41.90 \pm 2.94$ & $41.75 \pm 0.18$ \\
Lateral border & & \\
Tibia & $316.91 \pm 2.20$ & $318.10 \pm 3.83$ \\
Total & $63.82 \pm 4.05$ & $62.00 \pm 4.22$ \\
Width of proximal epiphysis & $22.29 \pm 1.14$ & $21.72 \pm 1.22$ \\
Width of diaphysis & $42.40 \pm 1.41$ & $43.12 \pm 3.06$ \\
Width of distal epiphysis & & \\
Metatars als & $194.64 \pm 11.12$ & $186.97 \mathrm{a}$ \\
Total & $32.12 \pm 3.16$ & $30.49^{\mathrm{a}}$ \\
Width of proximal epiphysis & $18.34 \pm 1.72$ & $17.34^{\mathrm{a}}$ \\
Width of diaphysis & $35.63 \pm 3.98$ & $31.76^{\mathrm{a}}$ \\
Width of distal epiphysis & & \\
an $=1$ & & \\
\hline
\end{tabular}

towards caudal. This projection presented differences between the studied specimens: "specimen-B" and "specimen-C" presented rough lines directed towards the lateral tubercle of the ischial tuberosity. "Specimen-A" presented two smooth lines, one towards the ischial tuberosity and the othertowards the ischial symphysis. Furthermore, different levels of ossification of the ischial symphysis were observed: in "specimen-A" both coxals were articulated, "specimen-B" presented a type of joint synostosis and "specimen- $\mathrm{C}$ " presented an incomplete ossification. The symphysis was found to have a concave shape dorsally and convex shape ventrally.

The pubis (os pubis), presented a characteristic " $r$ " shape and the groove of the accessory ligament of the femur. In the pubic symphysis, the ventral and dorsal pubic tubercles were observed. The iliopubic eminence was observed on its lateral side. Between the cranial ramus and the acetabulum there was a difference with respect to the presence of a notch or an obturator canal (incisura aut canalis obturatorius) that crossed the bone: in "specimen-A" it was semi-closed (notch) and the caudal 
margin had a small opening; in "specimen-B" it was completely closed (canal) with a robust bony bridge; and in "specimen-C" it was open (notch), flanked by laterally differentiated tubercles and the lateral side of the right canal less developed. The acetabulum presented a well circumscribed acetabular notch, and additional notches towards cranial and cranio-lateral. The lunate surface was smooth and had a greater and a smaller portion. The acetabular fossa with a round margin was observed in the middle. It projected caudally forming a tube with the caudal portion of the lunate surface. In "specimen-C" an acetabular fossa with a pyriform margin and elongated towards caudal was observed. In "specimen-A" the left acetabulum was smaller than its counterpart. The obturator foramen was oval with sharp and smooth margins, however, in "specimen-A" and "specimen-B" the medio-caudal margin had sharp and pointed spines (Fig. 1A).

Femur (os femoris) was slightly curved towards the cranial (Fig. 1B). The proximal epiphysis had three eminences: i) the femoral head (medial), which had the form of a smooth sphere protruding towards cranio-medial, it had a fovea for the insertion of the ligament of the head of femur, and a relatively smooth anatomical neck, deeper in "specimen-B "and "specimen-C"; ii) the major trochanter (lateral), hook-shaped in "specimen-A"; and iii) the minor trochanter (caudal), was pyramidal in shape. The latter presented a projection towards the diaphysis (distal) similar to a small ridge in "specimen-B", while it was more prominent and rougher in "specimen- $\mathrm{C}$ ". On the caudal aspect of the epiphysis, both trochanters converged through the intertrochanteric ridge, delimiting the trochanteric fossa, with a disto-medial obliquity. The diaphysis was cylindrical. In the middle of the proximal third of the cranial surface, the MNF was observed. This was slightly higher on the right side in "specimen-B" and "specimen- $\mathrm{C}$ ". The rough face, located on the caudal surface slightly towards lateral, was limited by a prominent lateral lip. At the distal end of the rough surface, the supra-condyloid fossa and the lateral supra-condylar tuberosity were observed. The narrowest section was right between the proximal third and the middle. Immediately proximal to the distal epiphysis the popliteal surface was observed, which was rough. Proximal to the medial condyle was located the medial supracondylar tuberosity. Overall, "specimen-B" and "specimen-C" presented more robust and defined muscle structures and insertion lines than "specimen-A". The distal epiphysis had three eminences: to cranial, the trochlea of the femoral bone, which lateral lip was sharp and thin, and medial lip was thick; to caudal, medial and lateral condyles were observed, the latter was slightly more prominent and larger than the medial, presenting on its lateral side the popliteal fossa. Each condyle had an epicondyle (epicondylus medialis et lateralis).
Between the lateral condyle and the trochlea -distally- the extensor fossa was observed. Between the condyles, from the base of the popliteal surface to the end of the trochlea, the inter-condyloid fossa extended. "specimen- $\mathrm{C}$ " further developed the major trochanter and the femoral trochlea on the right side, and "specimen-B" showed a larger major trochanter, medial condyle and femoral head on the left side. The shaft of femur has a radiopaque medial and lateral portion (dense or compact bone tissue) and a middle radiolucent portion (trabecular bone tissue). Both epiphyses, including the articular and non-articular eminences, had a large amount of trabecular bone tissue.

Patella (patella) was a pyramidal shape that protruded from the cranial side, rough towards proximal and smooth towards distal, and was the only sesamoid bone of the stifle joint. The base had three eminences, two big laterals and one cranial to lateral. Several nutrient foramina pitted the slightly roughened surface of the base. The apex was observed acute and elongated. The smooth articular face presented two grooves towards laterality.

The tibia (tibia) was slightly curved in its longitudinal axis (Fig. 1C). The proximal epiphysis presented the medial and lateral condyles, the latter being larger. Both articular facets conformed the proximal articular surface. Between the condyles, the cranial, central and caudal intercondylar areas were observed. Flanking the central intercondylar area, the medial and lateral intercondylar tuberosity were observed, corresponding to the intercondylar eminence. The extensor groove was smooth and well defined, flanked by two tuberosities. In the lateral margin of the lateral condyle, there were two spines projected toward distal, and only in "specimen-C" a rudimentary fibula was observed. The popliteal notch was well defined; however, it had a small tuberosity oriented medially. The diaphysis presented three surfaces: medial, lateral and caudal, and its cranial margin was defined by the extension of the tibial tuberosity distally. On its caudal surface, there was a small line. The distal twothirds of the diaphysis presented two smooth surfaces -cranial and caudal- with well-defined margins. On the cranial side, a line that was projected from the lateral margin of the proximal epiphysis was observed, reaching even the distal epiphysis. In the middle third of the diaphysis, the MNF oriented proximo-lateral was present. In "specimen-B" the MNF from the right side was slightly higher, whereas in "specimen- $\mathrm{C}$ " this condition was presented by the left one. On the caudal surface, a single line of the popliteus muscle (linea m. poplitei) was observed with disto-medial obliquity. The narrowest section was between the middle and distal third. Distal epiphysis presented the tibial cochlea which articulated with the talus. In the cranio-lateral surface, an eminence with two small spines was observed. In addition, the malleolar groove 
was present in the medial malleolus towards caudal. The shaft of tibia has a radiopaque medial and lateral portion of diaphysis (dense or compact bone tissue) and a middle radiolucent portion (trabecular bone tissue). Both epiphysis, including the articular and non-articular eminences, had a large amount of trabecular bone tissue, especially in the subchondral cortical plate of the condyles.

The skeleton of the foot (autopodium) comprised the bones of the tarsus (ossa tarsi, basidopodium), metatarsus (ossa metatarsalia, metapodium) and of the digits (ossa digitorum pedis, acropodium). In the proximal row of the tarsal bones were the calcaneus (lateral) and the talus (medial; Fig. 1D). The calcaneus was larger, with a latero-plantar position to the talus. Towards dorso-plantar, a prominent calcaneal tuberosity was observed, which presented two smooth surfaces that united in thick margins and a plantar margin, which had a tendinous sliding surface. At the base, a medium-sized coracoid process was observed, which presented an articular facet. The lateral surface was rough, it was projected forming the sustentaculum tali and a tendinous sliding surface over it (sulcus tendini m. flexoris digit. lateralis). The talus articulated with four tarsal bones. It presented two trochleae: proximal and distal. The lateral lip of the proximal trochlea was thicker and taller than the medial. The lips of the distal trochlea had the same height and articulated with the centroquartal bone. The distal row of the tarsal bones corresponded to the latter and to tarsal bones II and III, it presented proximal and distal joint faces. The proximal surface presented two glenoid foveas that articulated with the distal trochlea of the talus, andtowards the lateral side, a joint facet was seen that articulated with the calcaneus. The distal aspect had articular facets for articulation with the metatarsus-distally- and tarsal bone II and III, medially. The tarsal II and III bone were discoid, with articular facets that articulated proximally with the centroquartal bone and ventrally with the metatarsus. Metatarsal bones were similar to metacarpus and corresponded to the fusion of bones III and IV. The evidence of the bone fusion was the dorsal and plantar longitudinal groove. The narrowest section was between the proximal and middle third. The distal epiphysis presented two independent trochlea, each of them had two condyles (abaxial and axial) separated by a notch. The abaxial condyle was lower than the axial, but the latter had a larger surface area. None of the three studied skeletons had malleolar bone (os malleolare).

\section{DISCUSSION}

We have described the osteology of the pelvic skeleton only in three specimens mainly due to its conservation status and particularly due to thescarce amount of living specimens available for biometric studies, the regulatory mechanisms and difficult access to cadaverous material which makes it complex to obtain or manage it for scientific activity. Therefore, the presented morphological data are limited by sample size and by itself does not allow generalizations outside of the study area.

The coxal bone is elongated and narrow. Welldeveloped and prominent ventral iliac spines were observed, as well as a concave gluteal surface where powerful gluteal muscles are inserted. Also, a rough tendon insertion area for the rectus femoris muscle in the body of the ilium was observed. All this reflects the relevance of the hindlimb extension function, particularly of the coxofemoral and femorotibial joints. The thinnest area of the caudal third of the wing of the ilium observed in this species is associated with sharp spine-like rugosities in the caudal margin just cranial to the greater ischial notch, and could be the result of the presence of a ligament that could correspond to the broad sacrotuberous ligament. The latter appear to increase the surface of the iliac wings, probably forming part of the lateral wall of the birth canal. The gluteal side is almost vertical, similar to sheep and goats (Getty \& Sisson, 1975), but different from larger ungulates, such as cattle (Nickel et al., 1986). The gluteal surface, directed laterally in the Patagonian huemul, is similar to that observed in some domestic carnivores, such as dog and cat (Nickel et al.). In bovines, the iliopsoas muscle is double and powerful and consists of the fusion of psoas major and iliac muscles tendons in the minor trochanter (Nickel et $a l$.). In this last species, the surface of origin of the iliac muscle in the ventro-medial aspect of the iliac wing is very wide. However, the Patagonian huemul presented an elongated iliac wing and a small and relatively flat body. The ventro-medial aspect of the ilium wing is small and presented a ventro-lateral, almost vertical, obliquity. This suggests that the iliac muscle is small in this species, but we believe that it does not affect the flexion capacity of the coxofemoral joint, as it is supported by the presence of a prominent minor trochanter in the femur (Kardong, 2013).

The rounded acetabulum that was observed in the Patagonian huemul increases the efficiency of terrestrial locomotion, restricting the mobility of the femoral head in a parasagittal plane of the body. Sargis (2002) qualifies this type of movement as "pendulum type" in those animals where the rotation of the femur is not necessary.

In the pubis, the presence of an obturator canal was a focus of particular attention. This was large, well circumscribed and smooth, suggesting the passage of a neurovascular bundle. Tae et al. (2014) described the obturator canal in 26 species of deer worldwide, excluding the genera Hippocamelus, 
classifying them into 4 types according to their morphology and stage of development. In huemul, a type II canal was found in "specimen-B" - obturator notch, small indent in the cranial margin of the obturator foramen, obturator tubercles are formed - one of type III in "specimen-A" -canal virtually closed by spines of the obturator tubers- and one of type IV in "specimen$\mathrm{C}^{\prime \prime}$ - completely closed by a bony bridge -. This last variety was also described in the work of Tae et al., where it was found that 4 out of 16 species with more than one type of obturator canal presented 3 different morphologies for this structure. They also performed dissections confirming which nerve and vessels crossed the canal, these are the obturator nerve, the obturator artery (branch of the internal iliac artery, dorsal to obturator nerve) and the obturator branch of the medial circumflex femoral artery.

The femur is similar to what has been described in domestic ungulates (Nickel et al.), but less robust. The insertion and joint eminences are prominent. The minor trochanter, of caudomedial location, reduces the rotation associated with flexion of the femur and allows a more sagittal displacement. This has usually been associated with quadruped mammals where the hindlimb is used primarily as a propelling element (Fleagle \& Simons, 1995; Sargis). It was found that a characteristic of the deer femur was the absence of the third trochanter. It should be noted that a difference with domestic animals was the location of the MNF, which is on the cranial surface of the proximal half of the diaphysis. This suggests that blood is mainly supplied by the lateral circumflex femoral artery, which plays a predominant role in the irrigation of the cranial surface of the thigh and the rectus femoris muscle in Alpacas (Vicugna pacos) and Llamas (Lama glama; Angulo et al., 2013). The asymmetry of the femoral condyles observed in this study could indicate a pendular adduction movement during the gait and propulsion of the hindlimb (Fleagle \& Simons).

In tarsal bones, we observed a deep trochlea of the talus with a prominent lateral lip articulated to deep grooves of the tibial cochlea, which would act as a blockage to maintain pronation during locomotion, similar to that described in goats (Makungu, 2019). Therefore, this mechanism would prevent rotation, especially supination, and the movement of the tarsal joint would be restricted to only one axis, id est the extension and flexion for locomotion and propulsion.

The radiographic images reveal two types of tissues: compact and trabecular. The long bones, in general, show the effect of the pressure they support, particularly because the forces applied on them do not have a symmetrical distribution on the bone, generating a phenomenon where tension and compression forces are combined that eventually exceed the resistance of the bone. These forces are attenuated by the trabecular bone tissue - present in the epiphyses as opposed to the diaphysis - oriented in specific trajectories to support compression and traction (Oftadeh et al., 2015). In addition, as the long bone is a hollow cylinder, from the epiphysis resistant beams are observed that help to preserve the integrity of the compact bone tissue of the long bones, obtaining a greater resistance. Therefore, the radiographic images obtained in Patagonian huemul, confirm the epiphyseal function, which is to direct the forces along the diaphyseal axis in such a way that the resulting forces that act on the bone are centralized in a single direction, guaranteeing a better energy absorption and finally, preserving bone integrity. This information could be useful to investigate in future investigations regarding the displacement to the mountains of this deer - due to anthropic factors - and how the forces of tension and compression affect the bones.

In conclusion, the characteristics of bones and bony eminences present in the pelvic limb suggest the presence of powerful extensor muscles in the coxofemoral, femorotibial and tarsal joints, useful during walking, running and propulsion in deer. In general, the MNF of Patagonian huemul differ in position with respect to domestic ungulates. In addition, the presence of a notch or obturator canal was observed, with variability in morphology and development among the specimens. Also, this radiographic data can provide new information about the tissue loading conditions in Patagonian huemul, that cannot be obtained by other methods.

\section{ACKNOWLEDGEMENTS}

All stages of this study were conducted for scientific purposes only. The authors would like to thank: DI-PUCV 039.378/2019 Dirección de Investigación PUCV, Jhoann Canto of the National Museum of Natural History of Chile for providing skeletons of Patagonian huemul deer, Cecilia Altamirano of School of Veterinary Medicine of Universidad Santo Tomás of Chile for providing skeletons of domestic animals to compare and improve our discussion.

SALINAS, P.; ARENAS-CARO, A.; NÚÑEZ-COOK, S.; MORENO, L.; CURIHUENTRO, E. \& VIDAL, F. Estudio morfométrico, anatómico y radiográfico de los huesos del miembro pélvico de un ciervo patagónico en peligro de extinción (Hippocamelus bisulcus). Int. J. Morphol., 38(3):747-754, 2020.

RESUMEN: Actualmente, el Huemul Patagónico (Hippocamelus bisulcus) está en peligro de extinción. Los estudios morfológicos centrados en comprender su anatomía han sido un desafío para morfólogos, veterinarios y biólogos. Investigaciones enfocadas en su conservación, se han centrado principalmente 
en su ecología, patología y en la descripción de sus principales agentes infecciosos, dejando vacíos en el conocimiento anatómico básico, y por ende, su comprensión morfofisiológica. El objetivo de este estudio fue describir la anatomía, morfometría y radiología macroscópica normal y detallada del ossa membri pelvini en tres especímenes de Huemul Patagónico, incluida una interpretación funcional como referencia para uso clínico y conservacionista, investigación biomédica y fines de enseñanza. Los principales hallazgos sugieren la presencia de potentes músculos extensores en las articulaciones coxofemoral, femorotibial y tarsal, útiles durante la marcha, el trote y la propulsión en los ciervos. En general, los forámenes nutricios principales del Huemul patagónico difieren en posición con respecto a los ungulados domésticos. Además, se observó la presencia de una muesca o canal obturador, con variabilidad morfológica y de desarrollo entre los especímenes.

PAlabras Clave: Anatomía; Ciervo; Osteología; Huemul; Esqueleto; Fauna silvestre.

\section{REFERENCES}

Angulo, A. J.; Sato, S. A.; Navarrete, Z. M. \& Cisneros, S. J. Irrigación arterial del miembro pélvico de la alpaca (Vicugna pacos). Rev. Investig. Vet. Peru, 24(1):1-15, 2013.

Black-Decima, P. A.; Corti, P.; Díaz, N.; Fernandez, R.; Geist, V.; Gill, R.; Gizejewski, Z.; Jiménez, J.; Pastore, H.; Saucedo, C. \& Wittmer, H. Hippocamelus bisulcus. The IUCN Red List of Threatened Species, 2016. Available from: https://www.iucnredlist.org/species/10054/ 22158895

Corti, P.; Saucedo, C. \& Herrera, P. Evidence of bovine viral diarrhea, but absence of infectious bovine rhinotracheitis and bovine brucellosis in the endangered huemul deer (Hippocamelus bisulcus) in Chilean Patagonia. J. Wildl. Dis., 49(3):744-6, 2013.

Fleagle, J. G. \& Simons, E. L. Limb skeleton and locomotor adaptations of apidium phiomense, an Oligocene anthropoid from Egypt. Am. J. Phys. Anthropol., 97(3):235-89, 1995.

Flueck, W. T. \& Smith-Flueck, J. M. Hoof growth in neonatal Patagonian huemul (Hippocamelus bisulcus): a tentative tool for aging. Mastozool. Neotrop., 12(2):245-8, 2005.

Flueck, W. T. \& Smith-Flueck, J. M. Osteological comparisons of appendicular skeletons: a case study on Patagonian huemul deer and its implications for conservation. Anim. Prod. Sci., 51(4):327-39, 2014.

Getty, R. \& Sisson, S. Sisson and Grossman's the Anatomy of the Domestic Animals. $2^{\text {nd }}$ ed. Philadelphia, W. B. Saunders Company, 1975.

González-Acuña, D.; Saucedo, G. C.; Corti, P.; Casanueva, M. E. \& Cicchino, A. First records of the Louse Solenopotes binipilosus (Insecta: Phthiraptera) and the Mite Psoroptes ovis (Arachnida: Acari) from ild Southern Huemul (Hippocamelus bisulcus). J. Wildl. Dis., 45(4):12358, 2009.

International Committee on Veterinary Gross Anatomical Nomenclature (ICVGAN). Nomina Anatomica Veterinaria. $6^{\text {th }}$ ed. Hanover, Editorial Committee, 2017.

Kardong, K. V. Vertebrates: Comparative Anatomy, Function, Evolution. $7^{\text {th }}$ ed. Boston, McGraw-Hill Higher Education, 2013.

Makungu, M. Gross osteology and radiology of the pelvic limb of the adult small East African goat. Anat. Histol. Embryol., 48(3):234-43, 2019.

Morales, N.; Aldridge, D.; Bahamonde, A.; Cerda, J.; Araya, C.; Muñoz, R.; Saldías, M. E.; Lecocq, C.; Fresno, M.; Abalos, P.; et al. Corynebacterium pseudotuberculosis Infection in Patagonian Huemul (Hippocamelus bisulcus). J. Wildl. Dis., 53(3):621-4, 2017.
Nickel, R.; Schummer, A.; Seiferle, E.; Frewein, J.; Wilkens, H. \& Wille, K. H. The Anatomy of the Domestic Animals. Vol. 1. The Locomotor System of the Domestic Mammals. $5^{\text {th }}$ ed. Hamburg, Paul Parey, 1986.

Oftadeh, R.; Perez-Viloria, M.; Villa-Camacho, J. C.; Vaziri, A. \& Nazarian, A. Biomechanics and mechanobiology of trabecular bone: a review. $J$. Biomech. Eng., 137(1), 2015. Doi: 10.1115/1.4029176

Salgado, M.; Corti, P.; Verdugo, C.; Tomckowiack, C.; Moreira, R.; Durán, K.; Avilez, C. \& Tejeda, C. Evidence of Mycobacterium avium subsp . paratuberculosis (MAP) infection in huemul deer ( Hippocamelus bisulcus ) in patagonian fjords. Austral J. Vet. Sci., 49(2):135-7, 2017.

Sargis, E. J. Functional morphology of the hindlimb of tupaiids (Mammalia, Scandentia) and its phylogenetic implications. J. Morphol., 254(2):14985, 2002.

Tae, H. J.; Park, B. Y.; Kim, I. S. \& Ahn, D. Morphological examination of the obturator notch and canal in Cervidae. J. Vet. Med. Sci., 76(5):76771,2014

Vila, A. R.; Briceño, C.; McAloose, D.; Seimon, T. A.; Armién, A. G.; Mauldin, E. A.; Be, N. A.; Thissen, J. B.; Hinojosa, A.; Quezada, M.; et al. Putative parapoxvirus-associated foot disease in the endangered huemul deer (Hippocamelus bisulcus) in Bernardo O'Higgins National Park, Chile. PLoS One, 14(4):e0213667, 2019.

Vila, A. R.; López, R.; Pastore, H. \& Serret, A. Current distribution and conservation of the huemul (Hippocamelus bisulcus) in Argentina and Chile. Mastozool. Neotrop., 13(2):263-9, 2006.

Corresponding author:

Paulo Salinas

MorphoLAB - Institute of Biology

Faculty of Sciences

Pontificia Universidad Católica de Valparaíso

Av.Universidad \# 330, Curauma 3100000

Valparaíso

CHILE

Email: paulo.salinas@pucv.cl

ORCID: https://orcid.org/0000-0003-2273-0904

Received: 27-11-2019

Accepted: 12-02-2020 